\title{
An inhibitory alternative splice isoform of Toll-like receptor 3 is induced by type I interferons in human astrocyte cell lines
}

\author{
Jin-Won Seo ${ }^{1}$, Eun-Jeong Yang $^{1}$, Se Hoon $\mathrm{Kim}^{2} \mathcal{E}^{\mathrm{In}}$-Hong Choi ${ }^{1, *}$ \\ ${ }^{1}$ Department of Microbiology, Institute for Immunology and Immunological Diseases, and Brain Korea 21 PLUS Project for Medical Science, \\ ${ }^{2}$ Department of Pathology, Yonsei University College of Medicine, Seoul 03722, Korea
}

Toll-like receptor 3 (TLR3) recognizes viral double-stranded RNA. It stimulates pro-inflammatory cytokine and interferon production. Here we reported the expression of a novel isoform of TLR3 in human astrocyte cell lines whose message is generated by alternative splicing. The isoform represents the $\mathrm{N}$-terminus of the protein. It lacks many of the leucine-rich repeat domains, the transmembrane domain, and the intracellular Toll/interleukin-1 receptor domain of TLR3. Type I interferons (interferon- $\alpha$ and interferon- $\beta$ ) induced the expression of this isoform. Exogenous overexpression of this isoform inhibited interferon regulatory factor 3 , signal transducers and activators of transcription 1, and Inhibitor of kappa $B \alpha$ signaling following stimulation. This isoform of TLR3 also inhibited the production of chemokine interferon- $\gamma$-inducible protein 10. Our study clearly demonstrated that the expression of this isoform of TLR3 was a negative regulator of signaling pathways and that it was inducible by type I interferons. We also found that this isoform could modulate inflammation in the brain. [BMB Reports 2015; 48(12): 696-701]

\section{INTRODUCTION}

Toll-like receptor 3 (TLR3) is a pattern recognition receptor (PRR) that recognizes double-stranded RNA (dsRNA) during viral replication in endolysosomal compartments or on cell surfaces (1). Recognition of viral RNA by TLR3 triggers several intracellular signaling pathways that lead to activation of mitogen-activated protein kinases (MAPKs), nuclear factor $\kappa B$ (NF-kB), and interferon regulatory factor 3 (IRF3), resulting in the production of pro-inflammatory cytokines and type I interferons (IFNs) $(2,3)$. TLR3 is expressed in various kinds of cells, including dendritic cells, fibroblasts, intestinal epithelial cells, and astrocytes. Depending on the cell type, TLR3 represents

*Corresponding author. Tel: +82-2-2228-1821; Fax: +82-2-392-7088; E-mail: inhong@yuhs.ac

http://dx.doi.org/10.5483/BMBRep.2015.48.12.106

Received 1 June 2015, Revised 11 June 2015, Accepted 15 June 2015

Keywords: Astrocyte, Interferon, Isoform, Negative regulation, TLR3 different cellular response (4-6). Within distinct immunological milieu of the brain, TLR3 has been found to be necessary for the secretion of TNF- $\alpha$, IL-12p40, and IL- 6 in murine microglial cells after being stimulated by polyinosinic-polycytidylic acid (poly(l:C)) (7). In viral infections such as experimental infection with simian immunodeficiency virus and human immunodeficiency virus encephalitis, TLR3 expression is upregulated, leading to the induction of active innate immune responses in the brain (8). Following intracerebroventricular administration of poly(l:C) to mimic viral infection in the central nervous system, TLR3 signaling is activated, resulting in contextual memory and enhanced susceptibility to seizures $(9,10)$. Similar effects of viral infection on brain function have been reported in encephalitis and associated epileptic activity (1113). These reports suggest that inflammation as innate immune response is important in neurological disorders and in anti-viral defenses.

Astrocytes perform a variety of physiological functions such as forming the blood-brain barrier, transporting nutrients, and maintaining ion balances for the normal physiology of the brain. In addition, astrocytes play an important role in diseases related to neuro-inflammation $(14,15)$. Astrocytes express numerous PRRs to allow for the recognition of diverse pathogen-associated molecular patterns (PAMPs) (16-18). We have previously reported that TLR3 is expressed in astrocytes and that its activation induces the expression of IL-6 (19). We have reported that an isoform of TLR3 lacking $192 \mathrm{bp}$ is produced by alternative splicing in primary astrocytes and astrocyte cell lines (20). However, the mechanistic role of this isoform is unclear. In this study, we report a novel isoform of TLR3 that is induced by type I IFNs in astrocyte cell lines. It downregulated poly(l:C)-induced TLR3 signaling. This isoform might have an immune-modulatory function during brain inflammation and other pathological conditions.

\section{RESULTS}

An isoform of TLR3 is expressed in human astrocyte cell lines To investigate whether TLR3 has additional splice variants, we examined the expression level of TLR3 transcripts using different sets of primers corresponding to the 5'- or the 3'-UTR. A172 cells expressed a novel isoform of TLR3 that contained

ISSN: 1976-670X (electronic edition)

Copyright (C) 2015 by the The Korean Society for Biochemistry and Molecular Biology

c) This is an open-access article distributed under the terms of the Creative Commons Attribution Non-Commercial License (http://creativecommons.org/licenses/by-nc/4.0) which permits unrestricted non-commercial use, distribution, and reproduction in any medium, provided the original work is properly cited. 
A.

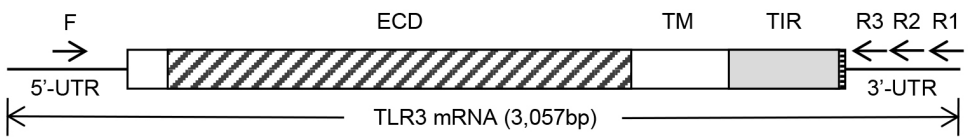

B.

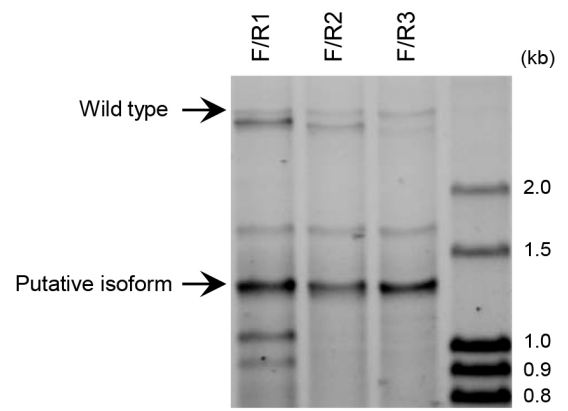

C.

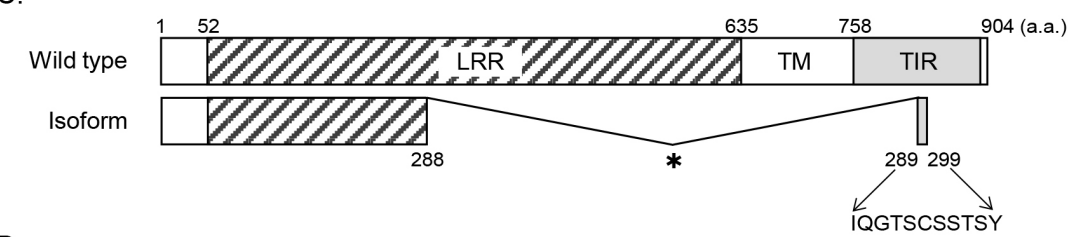

D.

1 cacttcgagagtgccgtctatttgccacacacttccctgatgaaatgtctggatttgg 60 actaaagaaaaaggaaaggctagcagtcatccaacagaatcatgagacagactttgcct $\begin{array}{lllllll}\mathbf{M} & \mathbf{R} & \mathbf{Q} & \mathbf{T} & \mathbf{L} & \mathbf{P}\end{array}$

120 tgtatctactttgggggggcetttgccetttgggatgctgtgtgcatcctccaccacc $\begin{array}{llllllllllllllllllll}\text { C } & \text { I } & \text { Y } & \text { F } & \text { W } & \text { G } & \text { G } & \text { L } & \text { L } & \text { P } & \text { F } & \text { G } & \text { M } & \text { L } & \text { C } & \text { A } & \text { S } & \text { S } & \text { T } & \text { T }\end{array}$

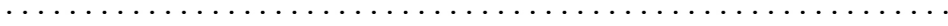
900 actttcttgggactaaagtggacaaatctcactatgctcgatcttcctacaacaactta $\begin{array}{llllllllllllllllllll}\mathbf{T} & \mathbf{F} & \mathbf{L} & \mathbf{G} & \mathbf{L} & \mathbf{K} & \mathbf{W} & \mathbf{T} & \mathbf{N} & \mathbf{L} & \mathbf{T} & \mathbf{M} & \mathbf{L} & \mathbf{D} & \mathbf{L} & \mathbf{S} & \mathbf{Y} & \mathbf{N} & \mathbf{N} & \mathbf{L}\end{array}$ 960 aatgtggttggtaacgattccttgcttggcttccacaactagaatatttcttcctagag $\begin{array}{llllllllllllllllllll}\mathbf{N} & -V & \text { V } & G & \mathbf{N} & \text { D } & \text { S } & \mathbf{F} & \text { A } & \text { W } & \text { L } & \text { P } & \text { Q } & \text { L } & \mathbf{E} & \mathbf{Y} & \mathbf{F} & \mathbf{F} & \text { L } & \mathbf{E}\end{array}$

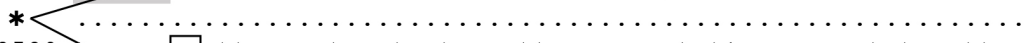
2580 tocaaagattcaaggtacatcatgcagttcaacaagctattgaacaaaatctggattcc $\begin{array}{lllllllllllllllllllll}C & K & R & F & K & V & H & H & A & V & Q & Q & A & I & E & Q & N & L & D & S\end{array}$

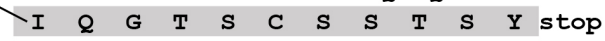

2640 attatattggttttccttgaggagattccagattataaactgaaccatgcactctgtttg $\begin{array}{llllllllllllllllllll}I & I & L & V & F & \text { L } & \mathbf{E} & \mathbf{E} & \mathbf{I} & \mathbf{P} & \mathbf{D} & \mathbf{Y} & \mathbf{K} & \mathbf{L} & \mathbf{N} & \mathbf{H} & \mathbf{A} & \mathrm{L} & \mathbf{C} & \mathrm{L}\end{array}$ 2700 cgaagaggaatgtttaatctcactgcatcttgaactggccagttcagaaagaacggata $\begin{array}{llllllllllllllllllll}R & R & G & M & F & K & S & H & C & I & I & N & W & P & V & O & K & E & R & I\end{array}$ 2760 ggtgccttcgtcataattgcaagtagcacttggatccaaaactctgtacattaatt $\begin{array}{lllllllllllllllllll}\mathbf{G} & \mathbf{A} & \mathbf{F} & \mathbf{R} & \mathbf{H} & \mathrm{K} & \mathrm{L} & \mathbf{Q} & \mathbf{V} & \mathbf{A} & \mathrm{L} & \mathbf{G} & \mathbf{S} & \mathrm{K} & \mathbf{N} & \mathbf{S} & \mathbf{V} & \mathbf{H} & \text { stop }\end{array}$
Fig. 1. Identification of a novel spliceisoform of human TLR3 in A172 cells. (A) Schematic diagram of wild type TLR3 gene with depiction of primer sets used for RT-PCR. (B) RT-PCR analysis of the wild type TLR3 and its novel isoform using mRNA from A172 cells. (C) Amino acid sequences of TLR3 and the novel TLR3 isoform. (D) cDNA and protein sequences of wild type TLR3 and its novel isoform. Numbers on the left indicate nucleotides, and numbers in parentheses on the right indicate amino acids. The asterisks indicate the portion missing from the isoform. The TLR3 isoform is related to wild type TLR3 by alternative splicing. The splice donor (gt) and acceptor (ag) sequences at positions 966-967 and 2,586-2,587, respectively, are in boxes. The splicing event introduces a frame-shift, resulting in the novel TLR3 isoform with a predicted protein sequence containing 299 amino acids shown in the grey box. an open reading frame of $900 \mathrm{bp}$ in length, including a stop codon. We obtained similar results using three different sets of primers (Fig. 1A, B). This isoform lacked the region of 9662,587 bp encoding a considerable number of the leucine rich repeat (LRR) domains, the transmembrane domain, and the intracellular toll/IL-1 receptor (TIR) domain responsible for signal transduction (Fig. 1C). The C-terminal 11 amino acids of this
TLR3 isoform differed from those of the TLR3 wild type as a result of a frame-shift introduced by alternative splicing. The alternative splicing occurred between the donor "GT" (region of 967-968 bp) and acceptor "AG" (region of 2,586-2,587 bp), introducing a frame-shift mutation and a stop codon "TGA" at region of 2,621-2,623 bp, resulting in translation of a 299 amino acid polypeptide (Fig. 1D). 


\begin{abstract}
IFN- $\alpha / \beta$ increases the transcript of the novel isoform of TLR3 in astrocyte cell lines

Upon viral infection, TLR3 will produce type I IFNs via activating IRF3. To assess the effect of type I IFNs on the transcription of the novel isoform of TLR3, A172 and NHA cells were treated with IFN- $\alpha$ or IFN- $\beta$. As a result, the transcription of this novel isoform of TLR3 was increased (Fig. 2A) after treatment with IFN- $\alpha$ or IFN- $\beta$. The transcript of this novel isoform of TLR3 was detectable starting at $3 \mathrm{~h}$ post treatment. Its level was increased until $24 \mathrm{~h}$ after IFN- $\beta$ treatment (Fig. 2B).
\end{abstract}

\section{Overexpression of the novel isoform of TLR3 inhibits TLR3 signaling}

Next, we determined whether the expression of the novel
TLR3 isoform would influence TLR3 signaling pathway induced by poly $(\mathrm{l}: \mathrm{C})$. Our results revealed that the poly(l:C) treatment induced phosphorylation of interferon regulatory factor 3 (IRF3), Inhibitor of kappa B $\alpha(\mathrm{I} \kappa \mathrm{B} \alpha)$, and signal transducers and activators of transcription 1 (STAT1) via TLR3 signaling in the control group (Fig. 3). When the isoform was exogenously overexpressed, phosphorylation levels of IRF3, I $\mathrm{KB} \alpha$, and STAT1 were significantly reduced compared to the mock transfection control (Fig. 3).

\section{Expression of the novel isoform of TLR3 affects the production} of interferon- $\gamma$-inducible protein 10 (IP-10)

To determine the effect of expression of the novel isoform of TLR3 on the secretion of antiviral chemokines, IP-10 was se-
A.

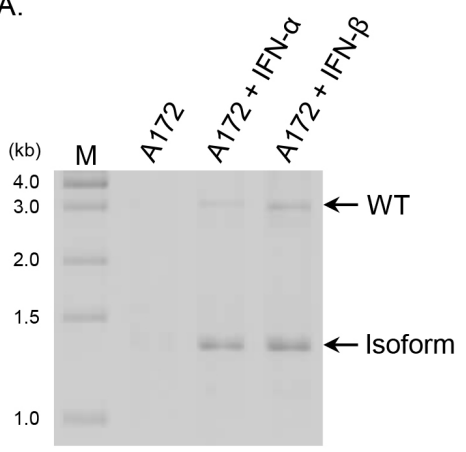

B.

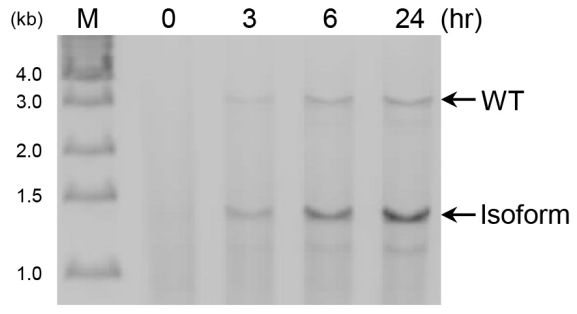

Fig. 2. The TLR3 isoform is a natural transcript in human astrocyte cell lines that is upregulated by type I IFNs. Both A172 (human glioblastoma) and NHA (normal human astrocyte) cells express wild type TLR3 and the novel isoform of TLR3. (A) A172 cells were treated with IFN- $\alpha$ and IFN- $\beta$ for 24 h. (B) NHA cells were treated with IFN- $\beta$ for the indicated time periods. $M$ denotes a $1-k b$ ladder as nucleotide size marker. The experiments were repeated five times and a representative result is shown.

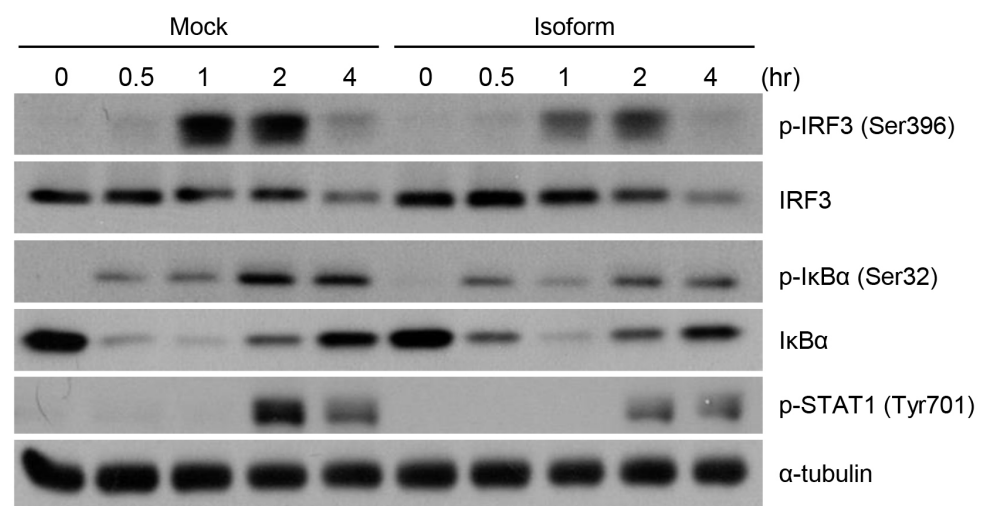

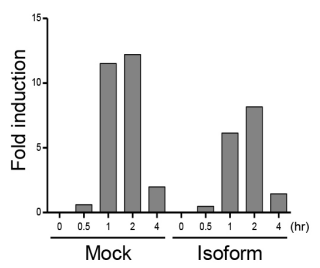

p-IRF3/a-tubulin

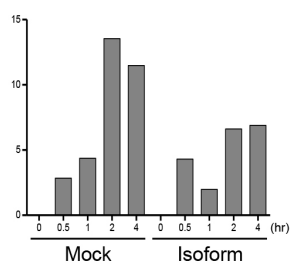

$\mathrm{p}-\mid \mathrm{kB} \alpha / \alpha$-tubulin

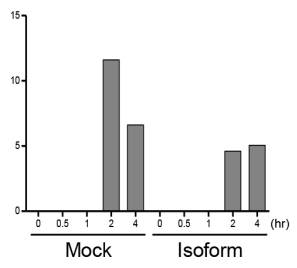

p-STAT / $\alpha$-tubulin
Fig. 3. Overexpression of the TLR3 isoform downregulates poly(l:C)-induced activation of IRF3, STAT1, and $I \kappa B \alpha$ in A172 cell lines. A172 cells were transfected with pCMV-Myc/TLR3 isoform and stimulated with $25 \mu \mathrm{g} / \mathrm{ml}$ of poly (I:C) for the indicated time periods. Total cell lysates were analyzed by immunoblotting using anti-phospho-IRF3 (Ser396), anti-IRF-3, anti-phospho-IкB $\alpha$ (Ser32), anti-I $\kappa \mathrm{B} \alpha$, anti-phospho-STAT1 (Tyr701), or anti-tubulin antibody. The experiments were repeated twice and a representative result is shown. 


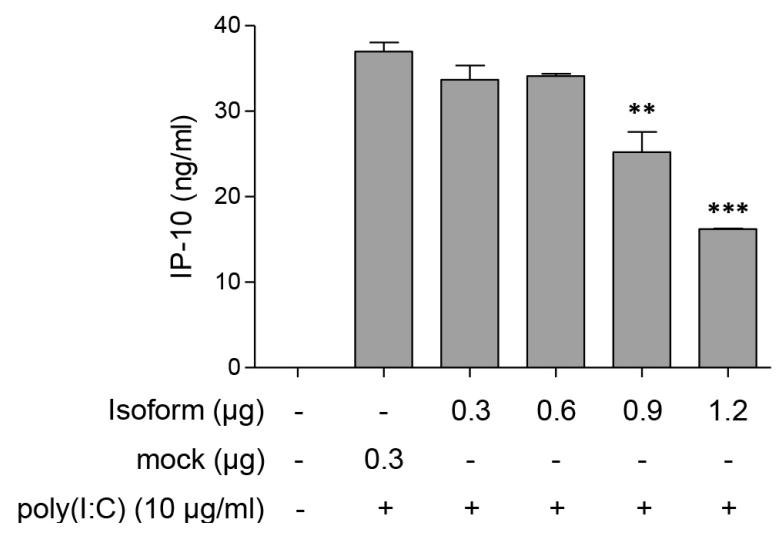

Fig. 4. Poly(I:C)-induced secretion of IP-10 was decreased by exogenous expression of the novel isoform of TLR3 in a dose-dependent manner. A172 cells were transiently transfected with pCMVMyc/TLR3 isoform (0.3-1.2 $\mu \mathrm{g})$, incubated for $24 \mathrm{~h}$, and stimulated with $10 \mu \mathrm{g} / \mathrm{ml}$ of poly(l:C) for $12 \mathrm{~h}$. Mock vector was transfected at $0.3 \mu \mathrm{g}$. Culture supernatants were harvested to measure the production of IP-10 by ELISA. Data represent mean \pm S.E. ${ }^{* P}<$ $0.05, * * \mathrm{P}<0.01, * * * \mathrm{P}<0.001$

lected as the major cytokine induced by TLR3 signaling. Upon ligation with poly(l:C), TLR3 stimulated IP-10 secretion via JAK/STAT pathway. Consistent with the inhibitory effect of TLR3 isoform expression on the activation of IRF3, I B $\alpha$, and STAT1 (Fig. 3), the production of IP-10 was decreased in a dose-dependent manner in cells exogenously overexpressing the TLR3 isoform (Fig. 4).

\section{DISCUSSION}

Endosomal TLRs such as TLR3, TLR7, and TLR9 can recognize nucleic acids derived from viruses and bacteria. They play important roles in innate immunity as well as pathological conditions (21). These TLRs can recognize self-DNA and RNA associated with several autoimmune diseases such as rheumatoid arthritis, systemic lupus erythematosus, and psoriasis (22, 23). Normally, self-nucleic acids are not detected by endosomal TLRs because there are several regulatory mechanisms, including receptor localization, association with accessory proteins, and proteolytic cleavage (24). For example, proteasemediated regulation of TLR depends on the type of protease that is active. When TLR9 is cleaved by acidic $\mathrm{pH}$-dependent protease such as cathepsins or asparagine endopeptidase, produced C-terminal cleaved fragments of TLR9 can augment TLR9 activation. On the other hand, when TLR9 is cleaved by neutral $\mathrm{pH}$-dependent proteases, produced $\mathrm{N}$-terminal fragments of TLR9 can inhibit TLR9 signaling $(25,26)$.

In the brain, TLR3 is abundantly expressed in microglia and astrocytes. TLR3 is active in anti-viral immune responses and some autoimmune diseases such as multiple sclerosis and experimental autoimmune encephalomyelitis $(27,28)$. Recent studies have shown that TLR3 cleavage by cysteine proteases will produce $\mathrm{C}$ - or $\mathrm{N}$-terminal fragments that are involved in the activation of the receptor (29-31).

In this study, we found a novel isoform of TLR3 generated by alternative splicing in astrocyte cell lines. This novel isoform has only LRRs $1-10$. It lacks the entire transmembrane and cytoplasmic TIR domains. The expression of this isoform was induced by the treatment with type I IFNs. Interestingly, when the isoform was exogenously overexpressed, poly(l:C)induced TLR3 activation was significantly reduced. Moreover, the secretion of IFN-responsive chemokine IP-10 was decreased in cells overexpressing this isoform. These negative regulatory effects of this TLR3 isoform may be caused by competition for ligand binding because this TLR3 isoform has dsRNA binding sites (LRR1 and LRR3), whereas it lacks the cytoplasmic TIR domain required for signal transduction $(25,32)$.

In summary, our results demonstrated that the expression of a novel isoform of TLR3 was induced by type I IFNs and that its protein product negatively regulated TLR3 activity. Therefore, this novel isoform of TLR3 might have immune-modulatory function in brain inflammation and some pathological conditions.

\section{MATERIALS AND METHODS}

\section{Reagents}

Poly(l:C) was purchased from Invivogen (San Diego, CA, USA). Recombinant human IFN- $\alpha$ and IFN- $\beta$ were purchased from ProSpec (East Brunswick, NJ, USA). Anti-phospho-IRF3 (Ser396),

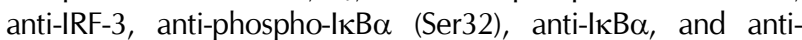
phospho-STAT1 (Tyr701) antibodies were purchased from Cell Signaling Technology Inc. (Danvers, MA, USA). Anti-tubulin antibody was purchased from Abcam (Cambridge, MA, USA).

\section{Cell culture}

Human glioblastoma cell line A172 was obtained from ATCC and cultured in DMEM medium containing $10 \%$ fetal bovine serum (FBS) and penicillin-streptomycin (100 units/ml and 100 $\mu \mathrm{g} / \mathrm{ml}$, respectively) at $37^{\circ} \mathrm{C}$ in a humidified $5 \% \mathrm{CO}_{2}$ incubator. Normal human astrocyte (NHA) cells were cultured in DMEM F-12 medium containing $10 \% \mathrm{FBS}, 10 \mu \mathrm{g} / \mathrm{ml}$ of blasticidin, 0.2 $\mu \mathrm{g} / \mathrm{ml}$ of puromycin, and penicillin-streptomycin (100 units/ml and $100 \mu \mathrm{g} / \mathrm{ml}$, respectively) at $37^{\circ} \mathrm{C}$ in a humidified $5 \% \mathrm{CO}_{2}$ incubator.

\section{RT-PCR}

A172 cells $\left(1 \times 10^{6}\right.$ cells per well $)$ were treated with or without IFN- $\alpha$ or IFN- $\beta$ ( 500 units $/ \mathrm{ml}$, respectively) for $24 \mathrm{~h}$. NHA cells $\left(5 \times 10^{5}\right.$ cells per well) were treated with IFN- $\beta$ (500 units $/ \mathrm{ml}$ ). After incubation, total RNA was isolated from A172 or NHA cells using RNeasy Mini kit (Qiagen, Santa Claris, CA, USA). A total of $2 \mu \mathrm{g}$ of total RNA was used to synthesize CDNA with random primers and M-MLV Reverse Transcriptase (Invitrogen). RT-PCR was performed using ex Taq polymerase 
(Takara, Tokyo, Japan). The following primers were used for RT-PCR: F (5'-GAA AGG CTA GCA GTC ATC CAA-3'), R1 (5'-CAA AAA TAG GCC TGA AAT AAG-3'), R2 (5'-TAT GAA TAA ACA AAT TAT AAC AC-3'), R3 (5'-TTT CTC CTT TGC TAA TTG AAT-3'). The following PCR conditions were used: denaturation at $94^{\circ} \mathrm{C}$ for $1 \mathrm{~min}$, annealing at $50^{\circ} \mathrm{C}$ for $30 \mathrm{~s}$, and extension at $72^{\circ} \mathrm{C}$ for $2 \mathrm{~min}$. After 30 cycles, an additional extension at $72^{\circ} \mathrm{C}$ for $10 \mathrm{~min}$ was performed. These primers were designed based on human TLR3 mRNA sequences obtained from GenBank (accession No. NM_003265.2).

\section{Cloning of the TLR3 isoform}

Total RNA was isolated from A172 cells $\left(1 \times 10^{6}\right.$ cells) using RNeasy Mini kit (Qiagen). A total of $3 \mu \mathrm{g}$ of total RNA was used for cDNA synthesis with M-MLV Reverse Transcriptase (Invitrogen) using forward (5'-G GCC ATG GAG GCC ATG AGA CAG ACT TTG CCT TGT ATC-3') and reverse (5'-CCG GAA TTC TCA ATA GCT TGT TGA ACT GCA TGA TGT-3') primers. A vector for TLR3 isoform expression was constructed by inserting PCR-amplified cDNA digested with Sfil and EcoRI into pCMV-Myc vector (Clontech, Palo Alto, CA, USA).

\section{Western blot}

A172 cells were cultured in 6-well plates at $3 \times 10^{5}$ cells per well and transiently transfected with $1 \mu \mathrm{g}$ of pCMV-Myc (mock) or pCMV-Myc/TLR3 isoform for $24 \mathrm{~h}$. Cells were stimulated with $25 \mu \mathrm{g} / \mathrm{ml}$ of poly(l:C) for indicated time periods. After stimulation, cells were harvested and lysed with lysis buffer $(150 \mathrm{mM}$ sodium chloride, $1.0 \%$ NP-40, $50 \mathrm{mM}$ Tris, $\mathrm{pH}$ 8.0) containing protease and phosphatase inhibitor cocktails (GenDEPOT, TX, USA). Cell lysates were centrifuged and supernatants were stored at $-80^{\circ} \mathrm{C}$. Protein concentrations of lysates were measured using Bradford protein assay. Fifty micrograms of each protein sample was separated by $12 \%$ SDSPAGE and transferred onto a nitrocellulose membrane (GE Healthcare, Waukesha, WI, USA). Membranes were incubated with anti-phospho-IRF3 (Ser 398), anti-IRF-3, anti-phospho-IкB $\alpha$

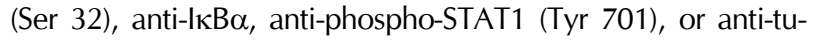
bulin antibody. Protein bands were detected using a West-save up western blot detection kit (Ab Frontier, Seoul, Korea).

\section{Enzyme-linked immunosorbent assay (ELISA)}

A172 cells were cultured in 6 -well plates at $3 \times 10^{5}$ cells per well and transiently transfected with 0.3-1.2 $\mu \mathrm{g}$ of pCMVMyc/TLR3 isoform using Fugene 6 reagent according to instructions of the manufacturer (Roche, Basel, Switzerland). Mock vector (pCMV-Myc) was transfected at $0.3 \mu \mathrm{g}$ per well. After $24 \mathrm{~h}$, cells were stimulated with $10 \mu \mathrm{g} / \mathrm{ml}$ of poly(l:C) for $12 \mathrm{~h}$. Culture supernatants were harvested and stored at $-80^{\circ} \mathrm{C}$. ELISA was performed with a human cytokine IP-10 assay kit (BD Bioscience, San Jose, CA, USA). The optical density (O.D.) at $450 \mathrm{~nm}$ was determined.

\section{Statistical analysis}

One-way ANOVA was performed for statistical analysis using PRISM version 5.01 (GraphPad Software, Inc., La Jolla, CA, USA). $\mathrm{P}<0.05$ was considered statistically significant.

\section{ACKNOWLEDGEMENTS}

This work was supported by the National Research Foundation of Korea (NRF) grant funded by the Korea government (MEST) (No. 2012R1A4A1029061).

\section{REFERENCES}

1. Matsumoto M, Oshiumi $\mathrm{H}$ and Seya T (2011) Antiviral responses induced by the TLR3 pathway. Rev Med Virol 21, 67-77

2. Hosokawa Y, Hosokawa I, Shindo S, Ozaki K and Matsuo T (2013) TLR3 agonist enhances CC chemokine ligand 20 production in IL-1beta-stimulated human gingival fibroblasts. Cell Immunol 283, 8-11

3. Yu M and Levine SJ (2011) Toll-like receptor, RIG--like receptors and the NLRP3 inflammasome: key modulators of innate immune responses to double-stranded RNA viruses. Cytokine Growth Factor Rev 22, 63-72

4. Farina C, Krumbholz M, Giese T, Hartmann G, Aloisi F and Meinl E (2005) Preferential expression and function of Toll-like receptor 3 in human astrocytes. J Neuroimmunol 159, 12-19

5. Olson JK and Miller SD (2004) Microglia initiate central nervous system innate and adaptive immune responses through multiple TLRs. J Immunol 173, 3916-3924

6. Matsumoto M, Funami K, Tanabe M et al (2003) Subcellular localization of Toll-like receptor 3 in human dendritic cells. J Immunol 171, 3154-3162

7. Town T, Jeng D, Alexopoulou L, Tan J and Flavell RA (2006) Microglia recognize double-stranded RNA via TLR3. J Immunol 176, 3804-3812

8. Suh HS, Brosnan CF and Lee SC (2009) Toll-like receptors in CNS viral infections. Curr Top Microbiol Immunol 336, 63-81

9. Galic MA, Riazi K, Henderson AK, Tsutsui S and Pittman QJ (2009) Viral-like brain inflammation during development causes increased seizure susceptibility in adult rats. Neurobiol Dis 36, 343-351

10. Riazi K, Galic MA and Pittman QJ (2010) Contributions of peripheral inflammation to seizure susceptibility: cytokines and brain excitability. Epilepsy Res 89, 34-42

11. Dakovic I, da Graca Andrada M, Folha T et al (2014) Clinical features of cerebral palsy in children with symptomatic congenital cytomegalovirus infection. Eur J Paediatr Neurol 18, 618-623

12. Singh TD, Fugate JE, Hocker SE and Rabinstein AA (2015) Postencephalitic epilepsy: clinical characteristics and predictors. Epilepsia 56, 133-138

13. Wilson JC, Toovey S, Jick SS and Meier CR (2014) Previously diagnosed influenza infections and the risk of developing epilepsy. Epidemiol Infect, 1-8

14. Sofroniew MV and Vinters HV (2010) Astrocytes: biology 
and pathology. Acta Neuropathol 119, 7-35

15. Le OT, Nguyen TT and Lee SY (2014) Phosphoinositide turnover in Toll-like receptor signaling and trafficking. BMB Rep 47, 361-368

16. Costello DA and Lynch MA (2013) Toll-like receptor 3 activation modulates hippocampal network excitability, via glial production of interferon-beta. Hippocampus 23, 696-707

17. Pan LN, Zhu W, Li Y et al (2014) Astrocytic Toll-like receptor 3 is associated with ischemic preconditioning-induced protection against brain ischemia in rodents. PLoS One 9, e99526

18. Nakajima A, Ibi D, Nagai T, Yamada $S$, Nabeshima $T$ and Yamada K (2014) Induction of interferon-induced transmembrane protein 3 gene expression by lipopolysaccharide in astrocytes. Eur J Pharmacol 745, 166-175

19. Kim H, Yang E, Lee J et al (2008) Double-stranded RNA mediates interferon regulatory factor 3 activation and interleukin- 6 production by engaging Toll-like receptor 3 in human brain astrocytes. Immunology 124, 480-488

20. Yang E, Shin JS, Kim H et al (2004) Cloning of TLR3 isoform. Yonsei Med J 45, 359-361

21. Sepulveda FE, Maschalidi S, Colisson R et al (2009) Critical role for asparagine endopeptidase in endocytic Toll-like receptor signaling in dendritic cells. Immunity 31, 737-748

22. Marshak-Rothstein A (2006) Toll-like receptors in systemic autoimmune disease. Nat Rev Immunol 6, 823-835

23. Krieg AM and Vollmer J (2007) Toll-like receptors 7, 8, and 9: linking innate immunity to autoimmunity. Immunol Rev 220, 251-269
24. Chockalingam A, Cameron JL, Brooks JC and Leifer CA (2011) Negative regulation of signaling by a soluble form of toll-like receptor 9. Eur J Immunol 41, 2176-2184

25. Ewald SE, Engel A, Lee J, Wang M, Bogyo $M$ and Barton GM (2011) Nucleic acid recognition by Toll-like receptors is coupled to stepwise processing by cathepsins and asparagine endopeptidase. J Exp Med 208, 643-651

26. Manoury B (2011) TLR9 regulation by proteolysis: a friend or a foe. Eur J Immunol 41, 2142-2144

27. Miranda-Hernandez S and Baxter AG (2013) Role of toll-like receptors in multiple sclerosis. Am J Clin Exp Immunol 2, 75-93

28. Touil T, Fitzgerald D, Zhang GX, Rostami A and Gran B (2006) Cutting Edge: TLR3 stimulation suppresses experimental autoimmune encephalomyelitis by inducing endogenous IFN-beta. J Immunol 177, 7505-7509

29. Murakami Y, Fukui R, Motoi Y et al (2014) Roles of the cleaved N-terminal TLR3 fragment and cell surface TLR3 in double-stranded RNA sensing. J Immunol 193, 5208-5217

30. Garcia-Cattaneo A, Gobert FX, Muller M et al (2012) Cleavage of Toll-like receptor 3 by cathepsins $B$ and $\mathrm{H}$ is essential for signaling. Proc Natl Acad Sci U S A 109, 9053-9058

31. Toscano F, Estornes Y, Virard F et al (2013) Cleaved/associated TLR3 represents the primary form of the signaling receptor. J Immunol 190, 764-773

32. Qi R, Singh D and Kao CC (2012) Proteolytic processing regulates Toll-like receptor 3 stability and endosomal localization. J Biol Chem 287, 32617-32629 